\title{
Retos educativos durante la pandemia de COVID-19: una encuesta a profesores de la UNAM
}

\author{
Melchor Sánchez Mendiola, Ana M. del Pilar Martínez Hernández, Ruth Torres \\ Carrasco, Mercedes de Agüero Servín, Alan K. Hernández Romo, Mario A. \\ Benavides Lara, Víctor J. Rendón Cazales y Carlos A. Jaimes Vergara
}

\begin{abstract}
Resumen
La contingencia provocada por la pandemia de la covid-19 (del inglés, coronavirus disease 2019) ha generado una situación inédita en los escenarios de la educación superior en México y en el mundo. Este documento reporta los resultados de una encuesta aplicada en línea a profesores de bachillerato, licenciatura y posgrado de la Universidad Nacional Autónoma de México (UNAM) el 25 de marzo de 2020. De una muestra de 788 docentes de la unAm, respondieron 383 (48.6\%), de los cuales 60.5\% están de acuerdo con el apoyo institucional que han recibido de la Universidad durante la contingencia. Las principales problemáticas a las que se enfrentan son logísticas (43.3\%), tecnológicas (39.7\%), pedagógicas (35.2\%) y socioafectivas (14.9\%). En cuanto al uso de la tecnología, para comunicación usan principalmente el correo electrónico, Facebook y WhatsApp; para trabajo académico, Google Classroom, Moodle y Google Suite; y para trabajo sincrónico, Zoom, Google Hangouts y Skype. En su mayoría, refieren requerir apoyo tecnológico y asesoría didáctica. A la pregunta abierta acerca de las propuestas que solicitan, en orden de importancia éstas son: formación pedagógica, disponibilidad de recursos digitales, recursos informativos sobre uso de tecnologías en educación, mejora de procesos institucionales, acompañamiento pedagógico, asesoría técnica e información de los recursos institucionales.
\end{abstract}

Palabras clave: contingencia educativa, educación superior, covid-19, educación mediada por tecnología, formación pedagógica.

Dol: http://doi.org/10.22201/codeic.16076079e.2020.v21n3.a12 
"Retos educativos durante la pandemia de CoviD-19: una encuesta a profesores de la UNAM"

\title{
EduCATIONAL CHALlenges dURING THE COVID-19 PANDEMIC: A TEACHERS' SURVEY AT UNAM
}

\begin{abstract}
The contingency generated by the covID-19 pandemic has created an unprecedented situation in higher education settings, in Mexico and globally. This document reports the results of an online survey applied on March 25, 2020, to National Autonomous University of Mexico (UNAM) teachers, from high school, college and graduate education levels. From a sample of 788 unAm teachers, 383 answered the questionnaire (48.6\%), from these $60.5 \%$ agreed with the support provided by the institution during the initial phase of the contingency. The main problems they deal with are: logistical (43.3\%), technological (39.7\%), pedagogical (35.2\%) and socioemotional (14.9\%). Regarding the use of technology, for communication tasks they use mainly e-mail, Facebook and WhatsApp; for academic work, Google Classroom, Moodle and Google Suite; and for synchronic activities, Zoom, Google Hangout and Skype. They require technological support and didactic counseling. To the open question about proposals, they request, in order of frequency: faculty development, availability of digital resources, information about educational uses of technology, improvement of institutional processes, pedagogical accompaniment, technical support and information of institutional resources.
\end{abstract}

Keywords: educational contingency, higher education, covid-19, technology mediated education, faculty development.

Melchor Sánchez Mendiola, Ana M. del Pilar Martínez Hernández, Ruth Torres Carrasco, Mercedes de Agüero Servín, Alan K. Hernández Romo, Mario A. Benavides Lara, Víctor J. Rendón Cazales y Carlos A. Jaimes Vergara

Grupo de trabajo de la Coordinación de Desarrollo Educativo e Innovación Curricular (CODEIC), Secretaría General, UNAM. 
"Retos educativos durante la pandemia de CoviD-19: una encuesta a profesores de la UNAM" Melchor S. Mendiola, María del Pilar M. Hernández, Ruth T. Carrasco, Mercedes de A. Servín, Alan K. Hernández Romo, Mario A. Benavides Lara, Víctor J. Rendón Cazales y Carlos A. Jaimes Vergara

Vol. 21, Núm. 3, mayo-junio 2020

Revista Digital Universitaria

\section{Introducción}

En diciembre de 2019 se originó en China una enfermedad viral por Coronavirus (covid-19) que se convirtió en unos meses en pandemia, con efectos devastadores para todos los integrantes de la sociedad (Yi et al., 2020). En el interconectado mundo moderno, la incertidumbre y sorpresa por lo rápido que se ha alterado la vida de prácticamente todos los habitantes del planeta ha creado una situación inédita para todas las organizaciones, incluyendo las instituciones de educación superior, quienes se han visto obligadas a suspender las actividades académicas cara a cara, en una transición abrupta y obligada a la educación a distancia mediada por tecnología (Sanz, 2020).

La suspensión obligatoria de las clases en todos los niveles educativos, con el confinamiento en casa de estudiantes y profesores, ha creado una red de efectos múltiples en todos los actores del proceso educativo. En el caso de las universidades, éstas han tenido que tomar una serie de medidas para acatar las indicaciones gubernamentales, al tiempo que intentan proporcionar a profesores y estudiantes con la infraestructura informática y tecnológica que les permita continuar con sus actividades académicas a distancia. Esta situación obligada para transitar de la educación universitaria presencial y escolarizada a modalidades no presenciales, mediadas por las tecnologías del aprendizaje y el conocimiento, puso de manifiesto las necesidades institucionales de infraestructura, sobre todo para repensar cómo se quiere que sea la transformación e implementación de la enseñanza, y la nueva cultura y práctica docentes.

Los docentes dejaron el salón de clase tradicional, al que han estado acostumbrados por décadas, para convertirse de manera obligada en usuarios de las herramientas tecnológicas que existen para interactuar a distancia entre ellos mismos y sus estudiantes, al tiempo que tienen que atender las presiones personales del confinamiento y sus implicaciones económicas, de salud y afectivas.

Por su parte, los estudiantes, que se encuentran súbitamente en su casa, comparten, si es que los hay, los dispositivos digitales y la red de internet que usa toda la familia, y tienen la necesidad de continuar sus actividades de aprendizaje de las diversas asignaturas inscritas, a través de tareas, conferencias virtuales y una serie de deberes que se superponen. Además, tienen que lidiar con los posibles efectos de la pandemia en la salud, las emociones, actividades físicas y las propias de la juventud (The Chronicle of Higher Education, 2020).

Esta combinación simultánea de entornos complejos ha creado un cóctel de acciones y emociones como nunca habíamos visto, que ha tomado prácticamente por sorpresa a las universidades, la comunidad de profesores, los estudiantes y la sociedad en general. Si a esto se le agrega la profunda incertidumbre, consecuencia de no saber cómo avanzará la pandemia en un 
"Retos educativos durante la pandemia de CoviD-19: una encuesta a profesores de la UNAM" Melchor S. Mendiola, María del Pilar M. Hernández, Ruth T. Carrasco, Mercedes de A. Servín, Alan K. Hernández Romo, Mario A. Benavides Lara, Víctor J. Rendón Cazales y Carlos A. Jaimes Vergara

Vol. 21, Núm. 3, mayo-junio 2020

Revista Digital Universitaria

país como México, de no saber si nosotros o nuestros seres queridos seremos víctimas de la infección y sus complicaciones, de la ausencia de una vacuna y tratamiento específico, y de la falta de certeza de cuándo regresaremos a nuestras actividades cotidianas y cuándo se reabrirán las universidades, el resultado es un pasmo que puede llevarnos a la parálisis, con consecuencias muy graves para el aprendizaje de los estudiantes. Sin embargo, es la oportunidad que tienen profesores y profesoras así como administradores de la educación superior de hacer una pausa y reflexionar atenta y sólida, científica y humanamente. También es el momento para explorar, tomar riesgos y enfrentar los desafíos tecnológicos, pedagógicas, didácticos y de los contextos de educación universitaria que son fundamentales para un aprendizaje profesional.

Ante el remolino del exceso de información acerca del avance de la pandemia, tenemos, en contraste, una ausencia de información sobre los efectos que está teniendo en los docentes de las instituciones de educación superior. Por ello, el objetivo de este estudio es reportar los resultados de un cuestionario que se aplicó a una muestra de profesores de la UNAM, para contar con información inicial de la realidad y los retos que enfrentan, y que sea útil para la toma de decisiones a corto, largo y mediano plazo.

\section{Material y método}

Este es un estudio exploratorio, no experimental y descriptivo, a través de un cuestionario en línea.

Escenario. La unAm es la universidad más importante de México, y una de las más grandes del mundo (UnAm, 2020). En el año 2015 se creó la Coordinación de Desarrollo Educativo e Innovación Curricular (CODEIC), una dependencia a nivel central supeditada a la Secretaría General, con una serie de funciones que tienen que ver con el desarrollo educativo, la innovación educativa, los planes y programas de estudios, la formación docente, la investigación en educación y la evaluación educativa, entre otras (www.codeic.unam.mx). Esta entidad académico-administrativa es la que realizó el estudio.

Muestra. Se recopiló una base de correos electrónicos de los participantes de educación continua de la coDeic, que en total son 1237 profesores. Se incluyeron sólo aquellos docentes cuyo correo electrónico tenía el dominio unam. mx o cuya dependencia de procedencia era de la UnAM, con lo que quedaron 892 participantes. Los usuarios son profesores de la UNAM de los tres niveles educativos (bachillerato, licenciatura y posgrado), que de manera espontánea han acudido en los últimos años a cursos, talleres y diplomados en la codelc. Así, es una muestra no probabilística e intencional, y por cuotas de profesores, según el nivel educativo en que imparten enseñanza. El cuestionario se contestó de manera voluntaria y en línea. 
"Retos educativos durante la pandemia de CoviD-19: una encuesta a profesores de la UNAM" Melchor S. Mendiola, María del Pilar M. Hernández, Ruth T. Carrasco, Mercedes de A. Servín, Alan K. Hernández Romo, Mario A. Benavides Lara, Víctor J. Rendón Cazales y Carlos A. Jaimes Vergara

Instrumento. Para su diseño se integró un grupo de cuatro académicos de la CODEIC, profesores de la UNAM de tiempo completo y de asignatura, con posgrado en educación superior. El objetivo del cuestionario es identificar los retos a los que se enfrentan los docentes universitarios, una vez que se declaró la suspensión de actividades presenciales y se transitó a las actividades en línea debido a la actual pandemia. Se acordaron las categorías de las problemáticas docentes a explorar, y se diseñó - por consenso - un cuestionario semiestructurado de 18 preguntas, siete de respuesta cerrada, diez de opción múltiple, en las que se pudo seleccionar más de una alternativa, y una pregunta abierta en la que se les solicitó a los profesores la redacción de propuestas a la UNAM. El cuestionario se encuentra disponible en el anexo 1.

Aplicación del cuestionario. Se realizó una depuración de los correos de los docentes tras corroborar la vigencia de las direcciones, a través del servicio Bouncer (https://usebouncer.com/), de la que resultó la cantidad de 788 correos válidos. Se envió el cuestionario de forma masiva y simultánea el 25 de marzo de 2020, dos direcciones fueron inválidas, por lo que fueron entregados 786 correos. Se incluyó un breve mensaje invitando a responder el cuestionario de forma voluntaria a través de la liga al instrumento en la plataforma de Google Forms; esta herramienta permitió capturar, monitorear y organizar las respuestas en tiempo real. Se envió a los profesores un recordatorio a las 48 horas, y se decidió realizar el análisis cuando se recibió cerca de 50\% de tasa de respuestas.

Análisis cuantitativo. Los resultados de Google Forms se exportaron a Google Sheets, para realizar la selección, traducción, transposición y codificación de los datos, y generar las estadísticas descriptivas y las gráficas de los resultados.

Análisis cualitativo. Este análisis abarcó las preguntas 8 a 17. Al ser las preguntas 8 a 16 cerradas, se agregó la opción de "Otra", para dejar la decisión a los docentes de incorporar otras problemáticas o herramientas que no estuvieran contempladas en las opciones cerradas. Las opciones de respuesta de la pregunta 8 (cuatro tipos de problemáticas: tecnológicas, pedagógicas, logísticas y socioafectivas) no están desagregadas en situaciones o problemáticas específicas; así, la información que los docentes proveyeron ayuda a tener una perspectiva general, pero, en la opción abierta, en muchos casos los docentes escribieron más de una problemática particular dada su experiencia durante la transición de la docencia presencial a la no presencial. La pregunta abierta número 17 se elaboró con la intención de que los docentes compartieran propuestas acerca de la forma en que consideran que la Universidad los puede apoyar en el contexto de la contingencia.

El análisis de la pregunta abierta y de las respuestas en "Otra" de las preguntas cerradas (de la 8 a la 16) se hizo a través de un análisis de las respuestas, lo que implicó leerlas, diferenciar sus temas, clasificarlas y agruparlas semánticamente (Van Dijk, 2000), para posteriormente agruparlas en categorías 
(Han, 2008), que permitieran identificar otras problemáticas a las que se están enfrentando los docentes, así como las propuestas concretas que tienen para que la Universidad los apoye.

\section{Resultados}

\section{Resultados cuantitativos}

Al quinto día de enviado el cuestionario, respondieron 383 docentes (48.6\% de la población encuestada), con lo que se hizo un cierre para el presente análisis. El registro de correos electrónicos de educación continua de la codelc está integrado por un porcentaje mayor de correos de profesoras mujeres (64\%), y menor de profesores hombres (36\%), lo que marca una diferencia inicial, según sexo, en la muestra de docentes que contestó el cuestionario.

El cuestionario fue respondido por 212 mujeres (55.4\%) y 166 hombres (43.3\%), distribuidos por edades como se puede ver en la figura 1.

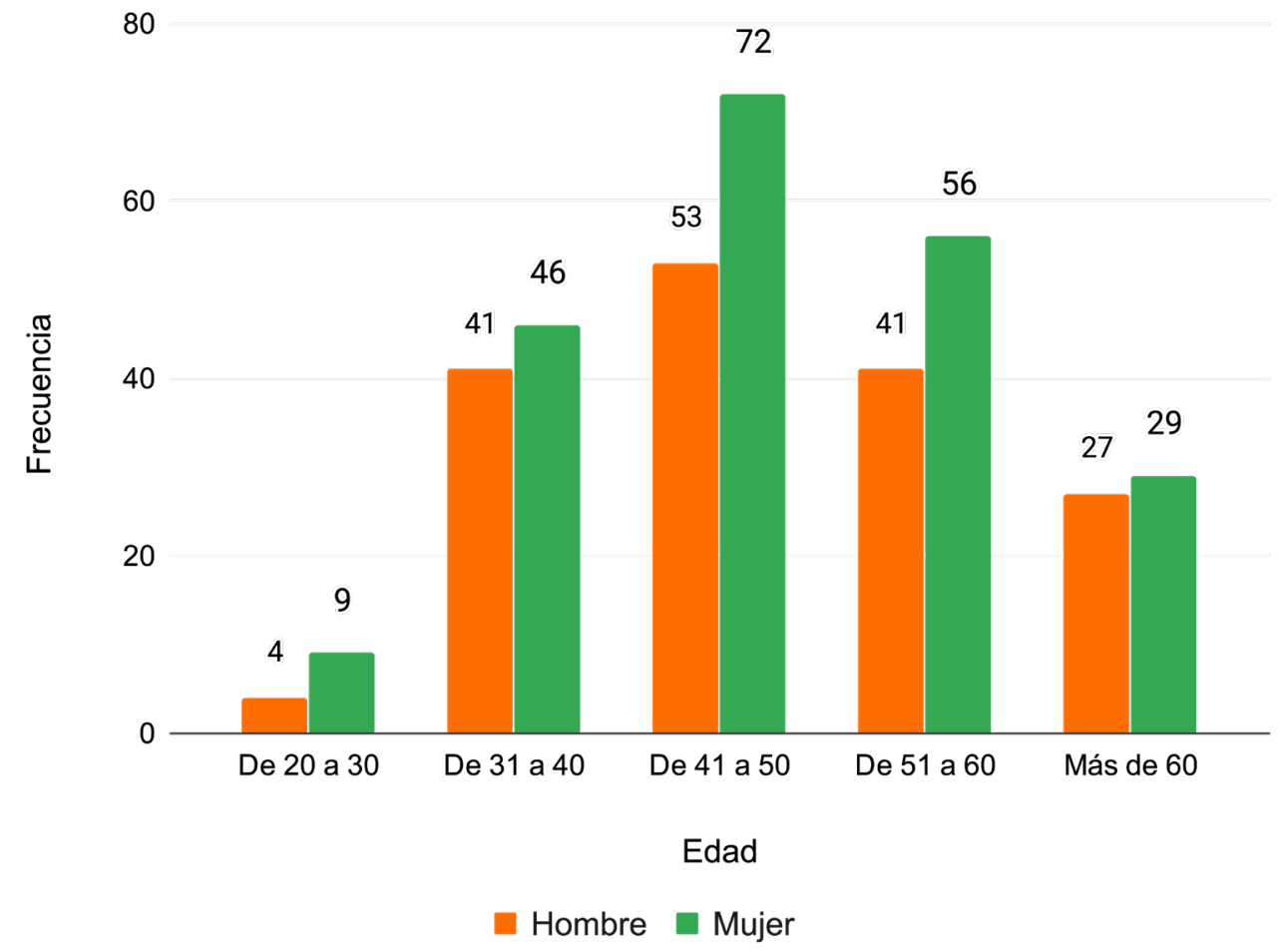

Respondieron 268 profesores de asignatura (70\%) y 115 profesores de carrera (30\%). En cuanto al nivel educativo en el que imparten clases, la mayoría fue de licenciatura (73.4\%, ver figura 2). 
"Retos educativos durante la pandemia de CoviD-19: una encuesta a profesores de la UNAM" Melchor S. Mendiola, María del Pilar M. Hernández, Ruth T. Carrasco, Mercedes de A. Servín, Alan K. Hernández Romo, Mario A. Benavides Lara, Víctor J. Rendón Cazales y Carlos A. Jaimes Vergara

Vol. 21, Núm. 3, mayo-junio 2020 Revista Digital Universitaria

Figura 2. Niveles educativos en los que imparten clases los docentes que respondieron el cuestionario ( $n=375)$. Suman más de 383 porque algunos docentes imparten clase en más de un nivel.

Figura 3. Número de grupos, por nivel educativo, a quienes imparten clases los docentes.

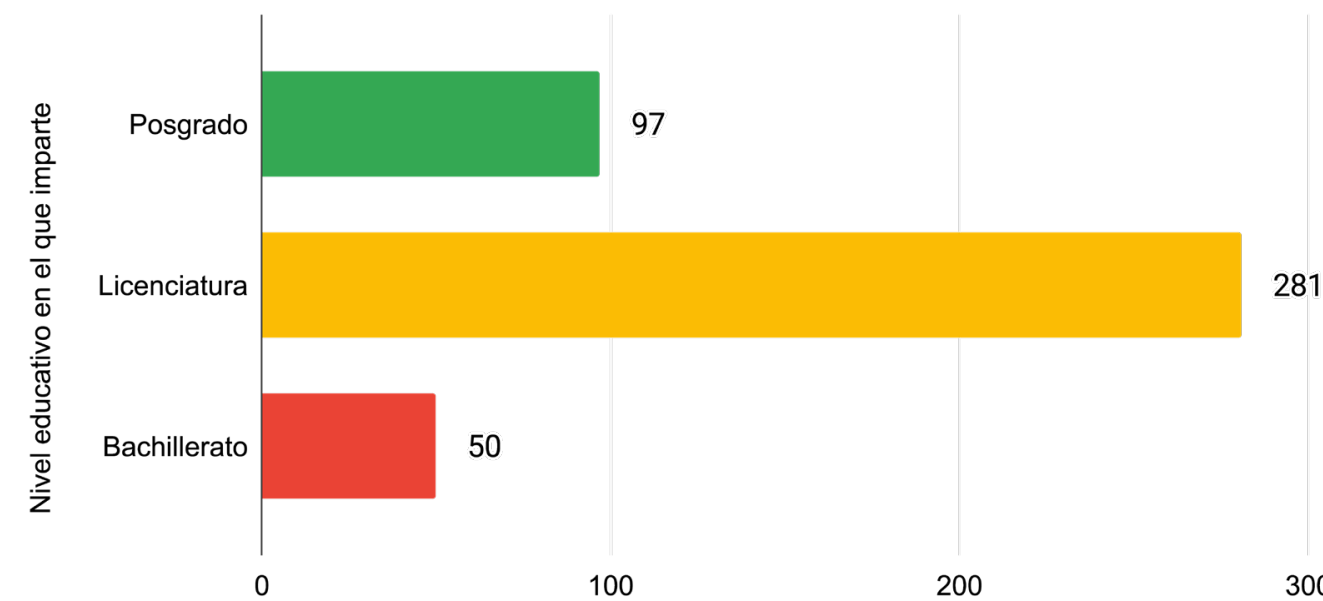

Número de profesores

En la pregunta acerca del número de grupos de estudiantes que atienden, la mayoría tiene de 1 a 3 grupos, aunque hay un número no trivial de docentes que tienen más de 3 grupos (ver figura 3).

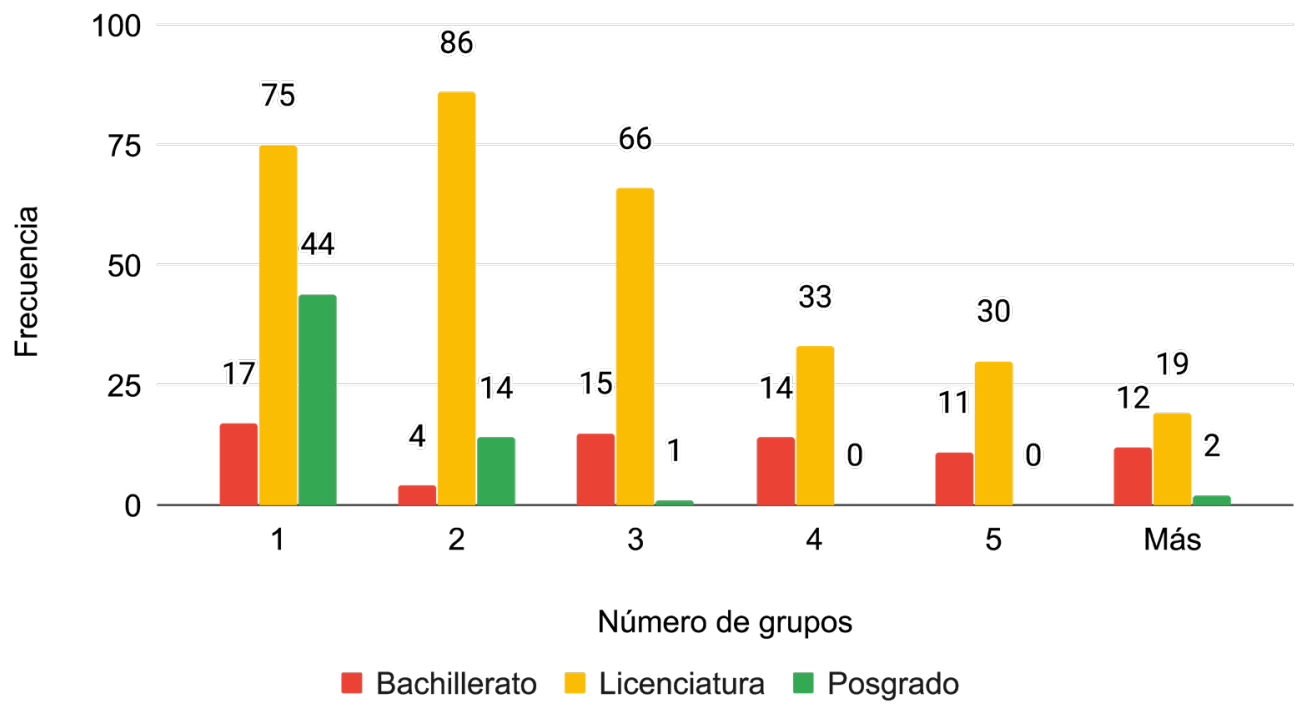

La mayoría de los docentes tiene menos de 40 estudiantes en promedio, aunque hay varios profesores que tienen más de 80 estudiantes, principalmente en bachillerato y licenciatura (ver figura 4). 
"Retos educativos durante la pandemia de CoviD-19: una encuesta a profesores de la UNAM" Melchor S. Mendiola, María del Pilar M. Hernández, Ruth T. Carrasco, Mercedes de A. Servín, Alan K. Hernández Romo, Mario A. Benavides Lara, Víctor J. Rendón Cazales y Carlos A. Jaimes Vergara

Figura 4. Número promedio de estudiantes que atiende cada profesor encuestado, por nivel educativo.

Figura 5. Grado de acuerdo con lo adecuado del apoyo institucional a los profesores al inicio de la contingencia.

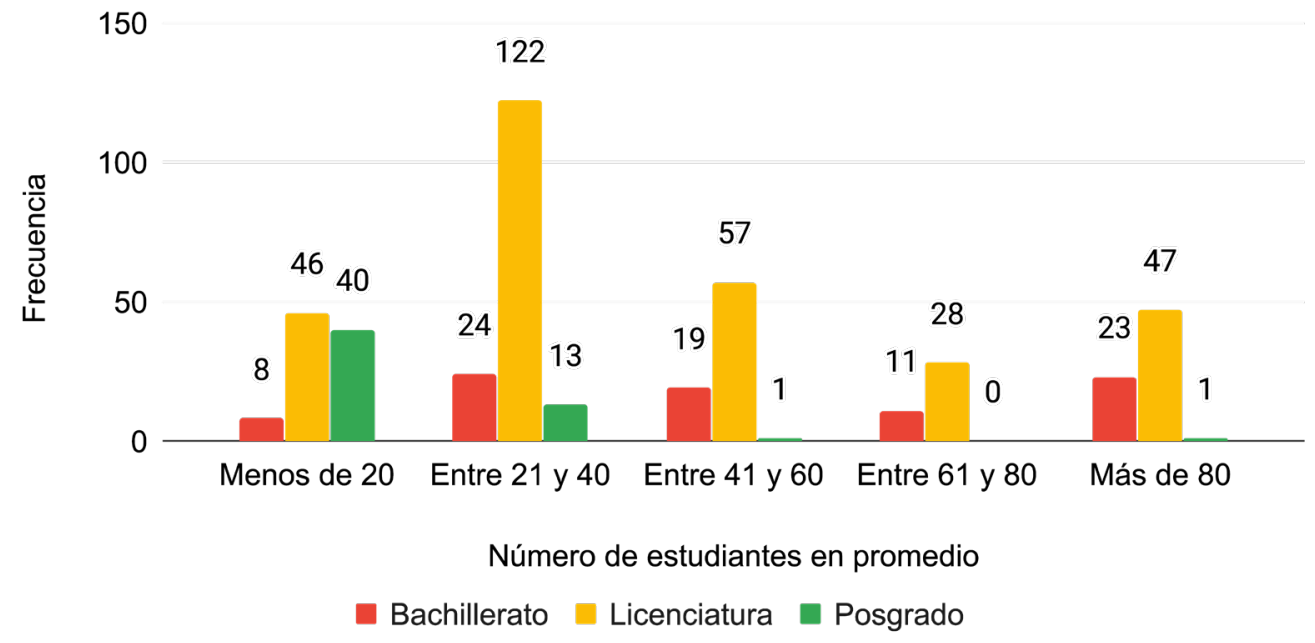

A la pregunta "El apoyo institucional que has recibido de la Universidad para transformar tus actividades docentes a distancia ha sido adecuado", 60.5\% de los encuestados respondió estar de acuerdo o totalmente de acuerdo (ver figura 5).

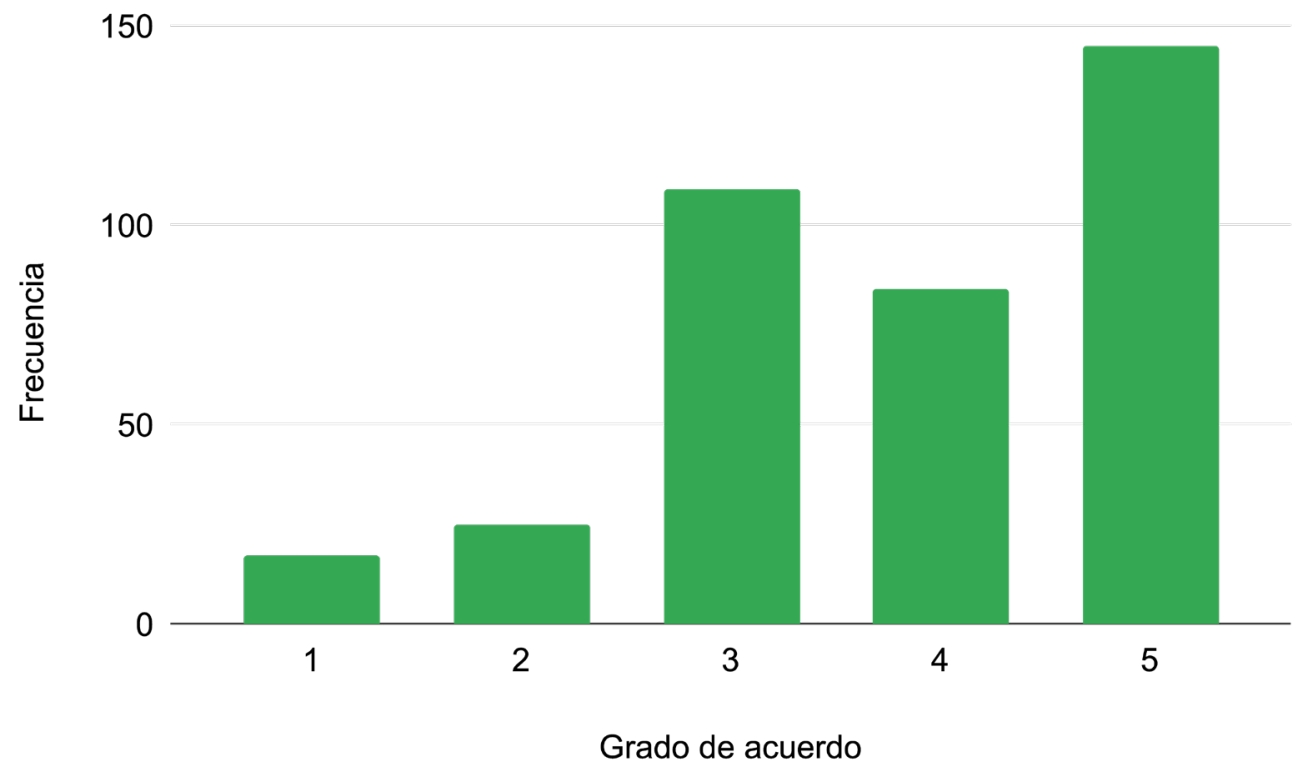

A la pregunta de si conocen el Campus Virtual de la unAm (https://distancia.cuaed. unam.mx), la herramienta institucional más importante para continuar la misión docente durante la contingencia, 54.7\% respondió que sí.

Acerca de los tipos de problemáticas a las que se están enfrentando para transformar sus actividades docentes a la modalidad a distancia, éstas se agruparon en cuatro tipos y consideran lo siguiente: 
"Retos educativos durante la pandemia de CoviD-19: una encuesta a profesores de la UNAM" Melchor S. Mendiola, María del Pilar M. Hernández, Ruth T. Carrasco, Mercedes de A. Servín, Alan K. Hernández Romo, Mario A. Benavides Lara, Víctor J. Rendón Cazales y Carlos A. Jaimes Vergara

Vol. 21, Núm. 3, mayo-junio 2020 Revista Digital Universitaria

- Logísticas. Se refieren a circunstancias relacionadas con el manejo del tiempo, los horarios de clase, los espacios físicos para trabajar a distancia, la comunicación institucional, entre otras.

- Tecnológicas. Se refieren a circunstancias relacionadas con el acceso a internet, la disposición de equipos de cómputo, los conocimientos de plataformas educativas, entre otras.

- Pedagógicas. Se refieren a circunstancias relacionadas con el conocimiento de herramientas didácticas de educación a distancia, el manejo de grupos a distancia, la evaluación de los estudiantes, entre otras.

- Socioafectivas. Se refieren a circunstancias relacionadas con aspectos emocionales, afectivos y de la salud que viven los docentes, como sentimientos de tristeza, frustración, ansiedad, cansancio, entre otras.

Se encontró que las problemáticas más frecuentes de los profesores son las logísticas (43.3\%), seguidas por las tecnológicas (39.7\%), después las pedagógicas (35.2\%) y en menor proporción las socioafectivas (14.9\%) (ver figura 6). En esta pregunta, los profesores encuestados también tenían la opción de contestar "Otros" y manifestar de manera explícita la problemática a la que se enfrentan. El análisis de las respuestas con la opción abierta se detalla en la sección acerca de los "Resultados cualitativos", en el apartado de la pregunta 8.

Figura 6. Problemáticas más frecuentes a las que se enfrentan los docentes y los estudiantes (desde la perspectiva de los docentes), para transformar su práctica hacia una modalidad no presencial.
Docentes

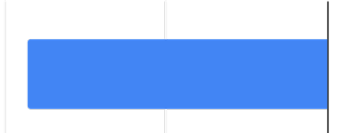

$43.3 \%$

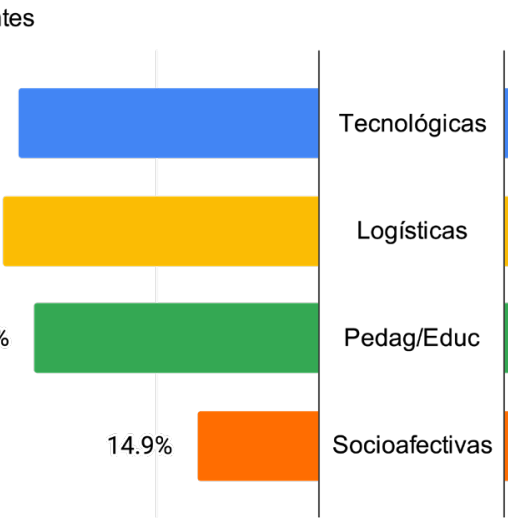

$60.0 \%$

$40.0 \%$
$0.0 \%$
Alumnos
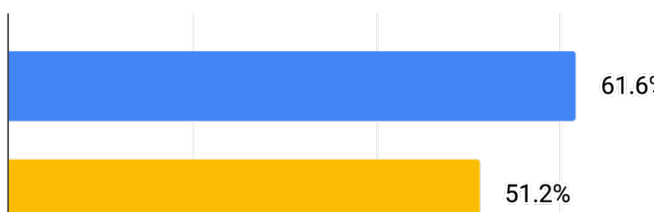

$39.2 \%$

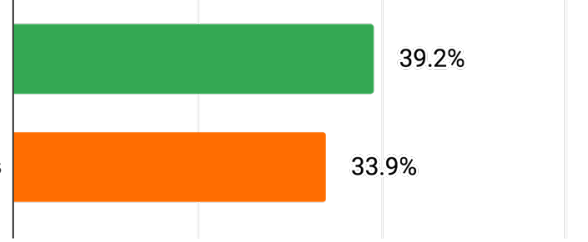

$20.0 \% \quad 40.0 \%$

Los tipos de problemáticas que enfrentan los estudiantes para continuar sus estudios durante la contingencia, desde la perspectiva de los docentes, se clasificaron de la siguiente manera:

- Tecnológicas. Se refieren a circunstancias relacionadas con el acceso a internet, disposición de equipos de cómputo, conocimientos de plataformas educativas, entre otras.

- Logísticas. Se refieren a circunstancias relacionadas con el manejo del tiempo, los horarios de clase, los espacios físicos para trabajar a distancia, la comunicación institucional, entre otras. 
"Retos educativos durante la pandemia de CoviD-19: una encuesta a profesores de la UNAM" Melchor S. Mendiola, María del Pilar M. Hernández, Ruth T. Carrasco, Mercedes de A. Servín, Alan K. Hernández Romo, Mario A. Benavides Lara, Víctor J. Rendón Cazales y Carlos A. Jaimes Vergara

- Educativas. Se refieren a circunstancias relacionadas con el conocimiento de herramientas de educación a distancia, la participación a distancia, envío de actividades y tareas, entre otras.

- Socioafectivas. Se refieren a circunstancias relacionadas con aspectos emocionales, afectivos y de salud que viven los estudiantes como sentimientos de tristeza, frustración, ansiedad, cansancio, falta de motivación, aburrimiento, entre otras.

Se encontró que las problemáticas del estudiante, desde la perspectiva del docente, con más frecuencia son las tecnológicas (61.6\%), seguidas por las logísticas (51.2\%), posteriormente las educativas (39.2\%) y, por último, las socioafectivas (33.9\%) (ver figura 6). En esta pregunta los profesores encuestados también tenían la opción de contestar "Otras" problemáticas y manifestar de manera específica a cuáles se enfrentan. Como ya se mencionó, el análisis de las respuestas abiertas se detalla en la sección de los "Resultados cualitativos", en este caso dicho análisis se encuentra en el apartado de la pregunta 9.

Los recursos tecnológicos utilizados para el trabajo docente a distancia se agruparon en cuatro tipos:

- De comunicación. Se consideran los recursos como Facebook, Twitter, WhatsApp y correo electrónico.

- De trabajo académico. Se consideran los recursos como Moodle, Google Suite, Google Classroom y Teams.

- De almacenamiento. Se consideran los recursos como Dropbox y Google Drive.

- De trabajo sincrónico. Se consideran los recursos como Skype, Google Hangouts y Zoom.

Los recursos tecnológicos más utilizados fueron los de comunicación (75.2\%), seguidos por los de trabajo académico (63.4\%), después los de almacenamiento (49.3\%) y con menos proporción los de trabajo sincrónico (39.9\%) (ver figura 7).

Figura 7. Tipos de recursos tecnológicos utilizados por los docentes de la unam.

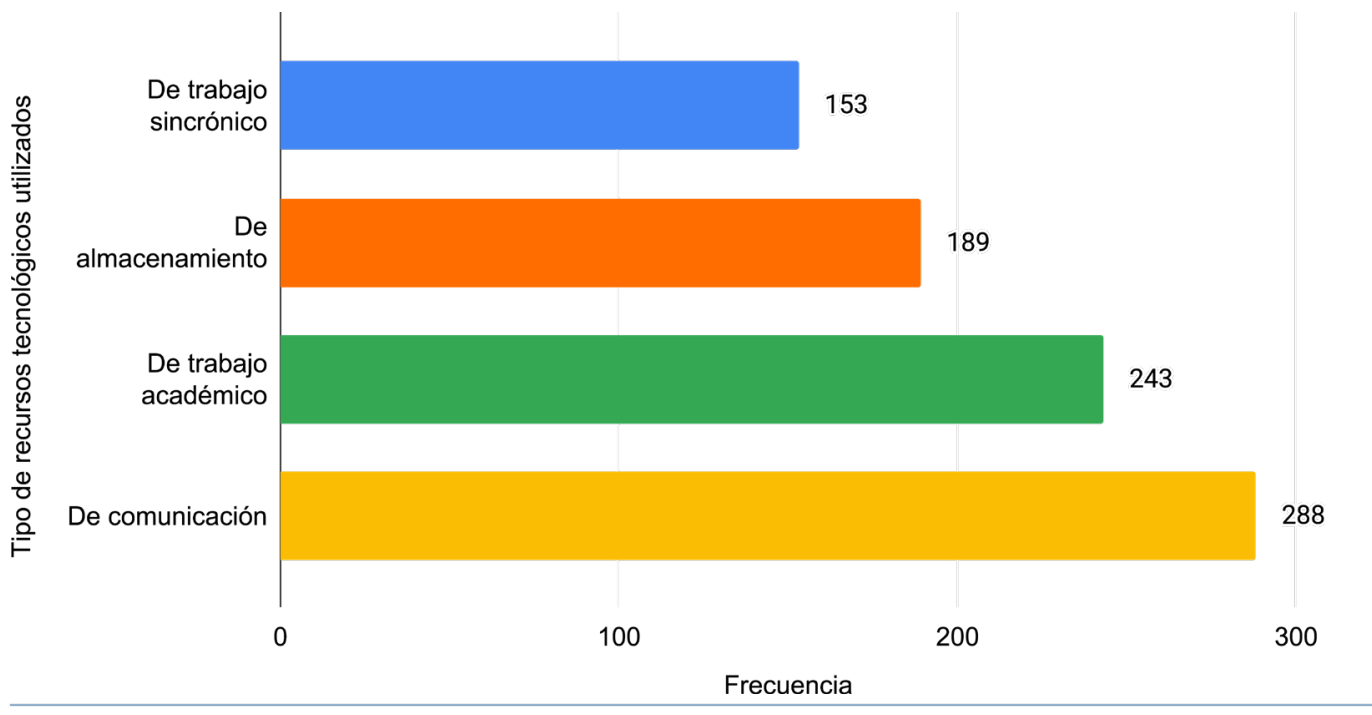


A continuación, se presentan desglosados los recursos tecnológicos utilizados por los docentes, con base en la clasificación descrita arriba (ver figuras 8 a 11).

400

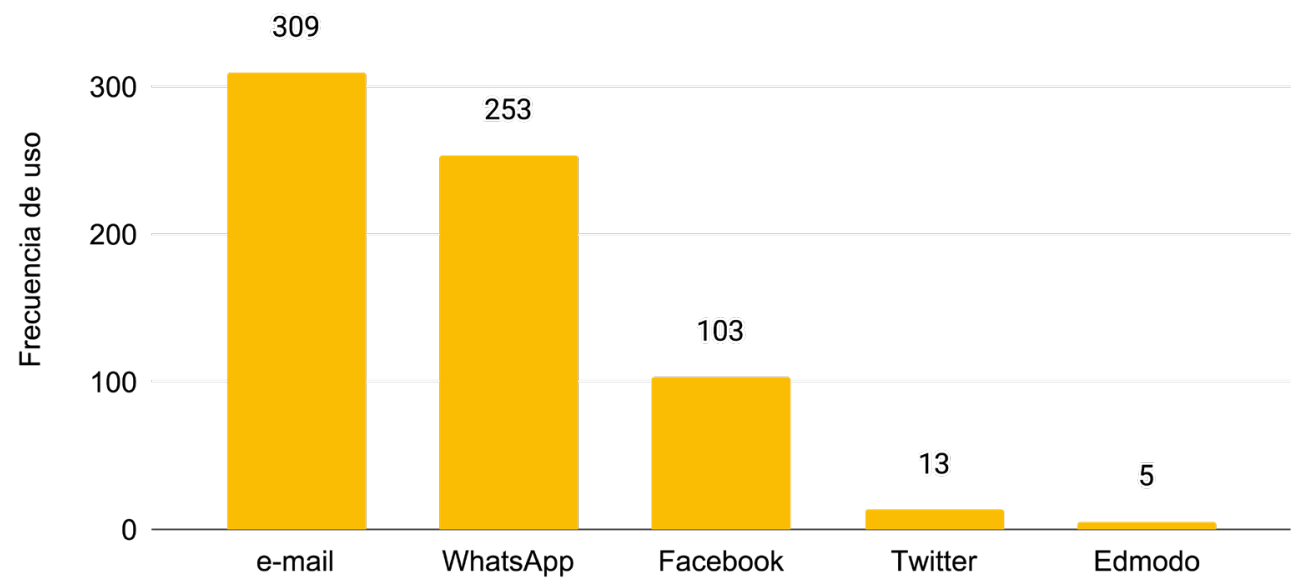

Figura 8. Uso de recursos tecnológicos por parte de los profesores para comunicación.

Figura 9. Uso de recursos tecnológicos por parte de los profesores para trabajo académico.

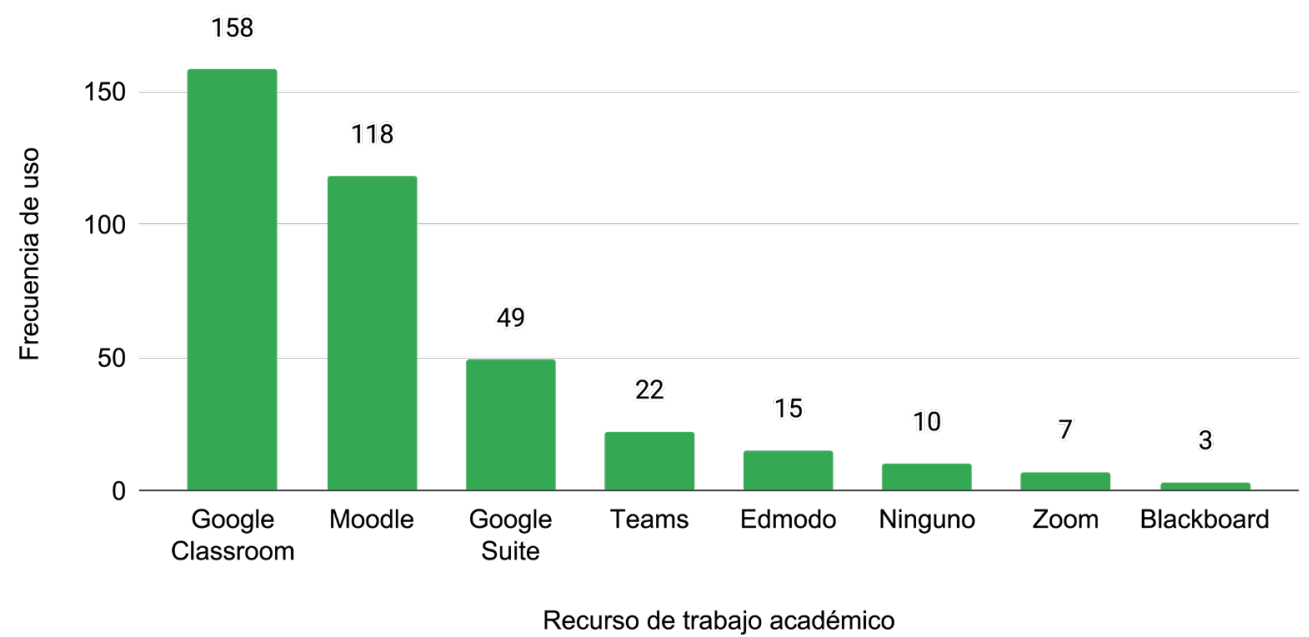


Figura 10. Uso de recursos tecnológicos de almacenamiento por parte de los profesores.

Figura 11. Uso de recursos tecnológicos por parte de los profesores para trabajo sincrónico.

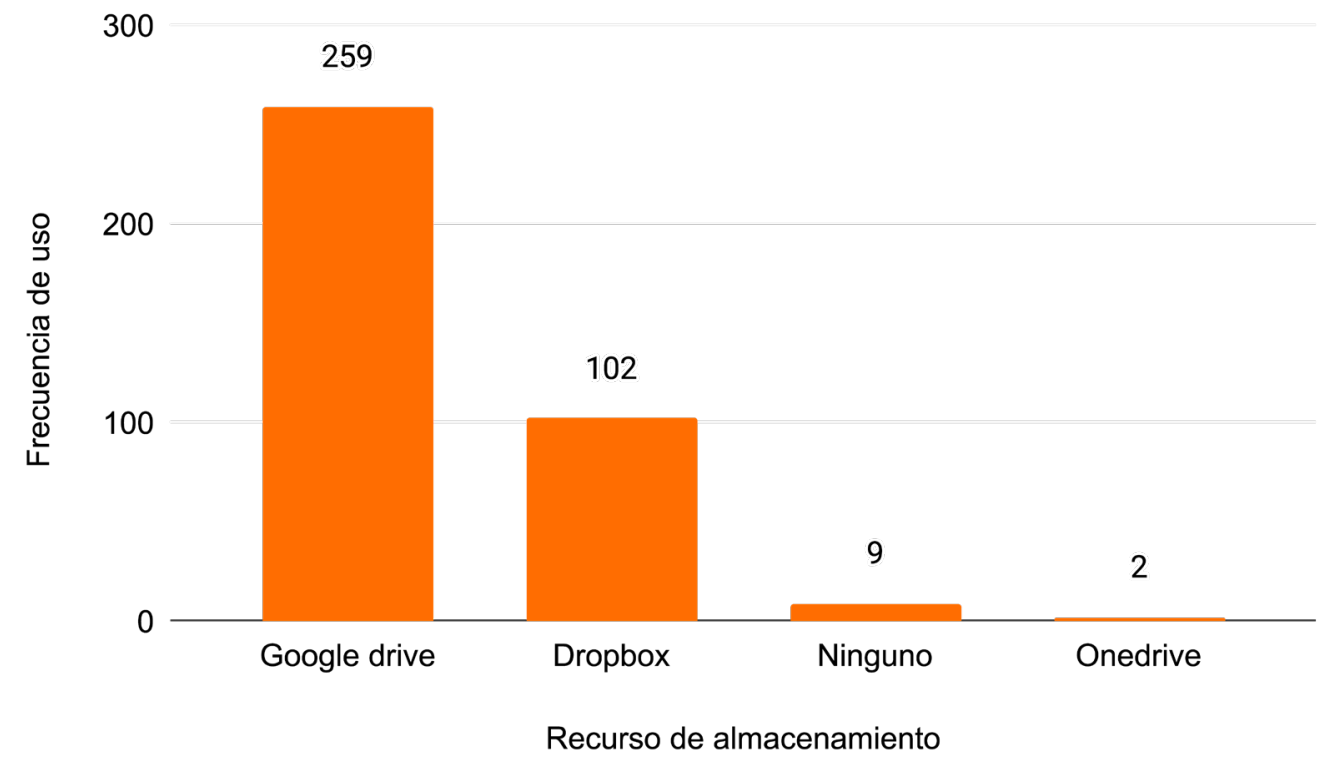

200

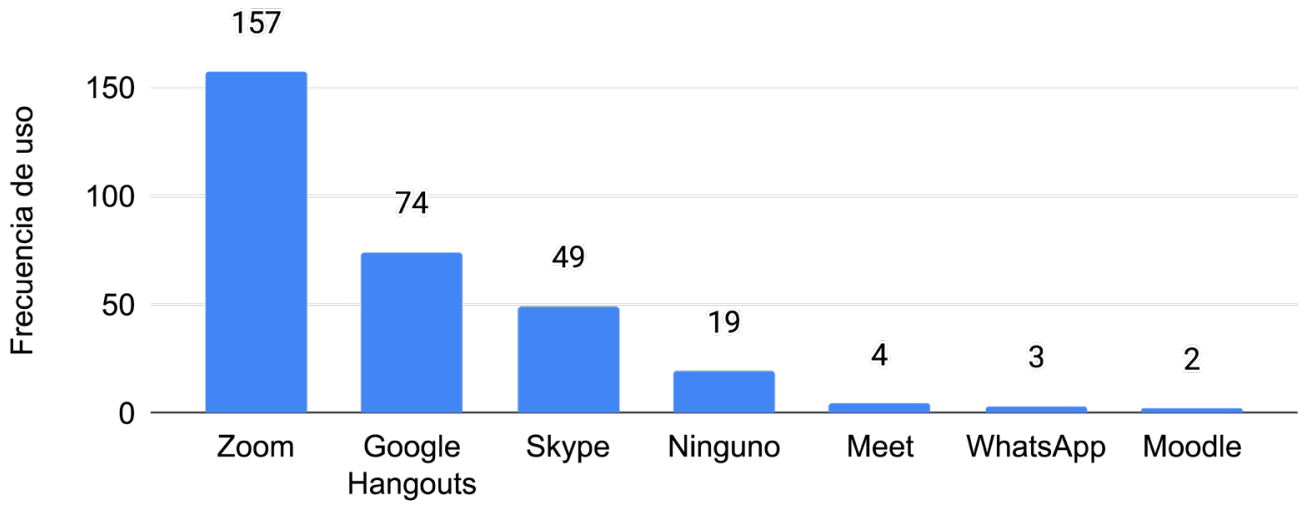

Recurso de trabajo sincrónico

A la pregunta de cuáles recursos tecnológicos les interesa aprender a utilizar para sus actividades docentes a distancia, respondieron con los datos de la figura 12. 
"Retos educativos durante la pandemia de CoviD-19: una encuesta a profesores de la UNAM" Melchor S. Mendiola, María del Pilar M. Hernández, Ruth T. Carrasco, Mercedes de A. Servín, Alan K. Hernández Romo, Mario A. Benavides Lara, Víctor J. Rendón Cazales y Carlos A. Jaimes Vergara

Figura 12. Variedad de recursos tecnológicos que los docentes desean aprender a utilizar para la educación no presencial.

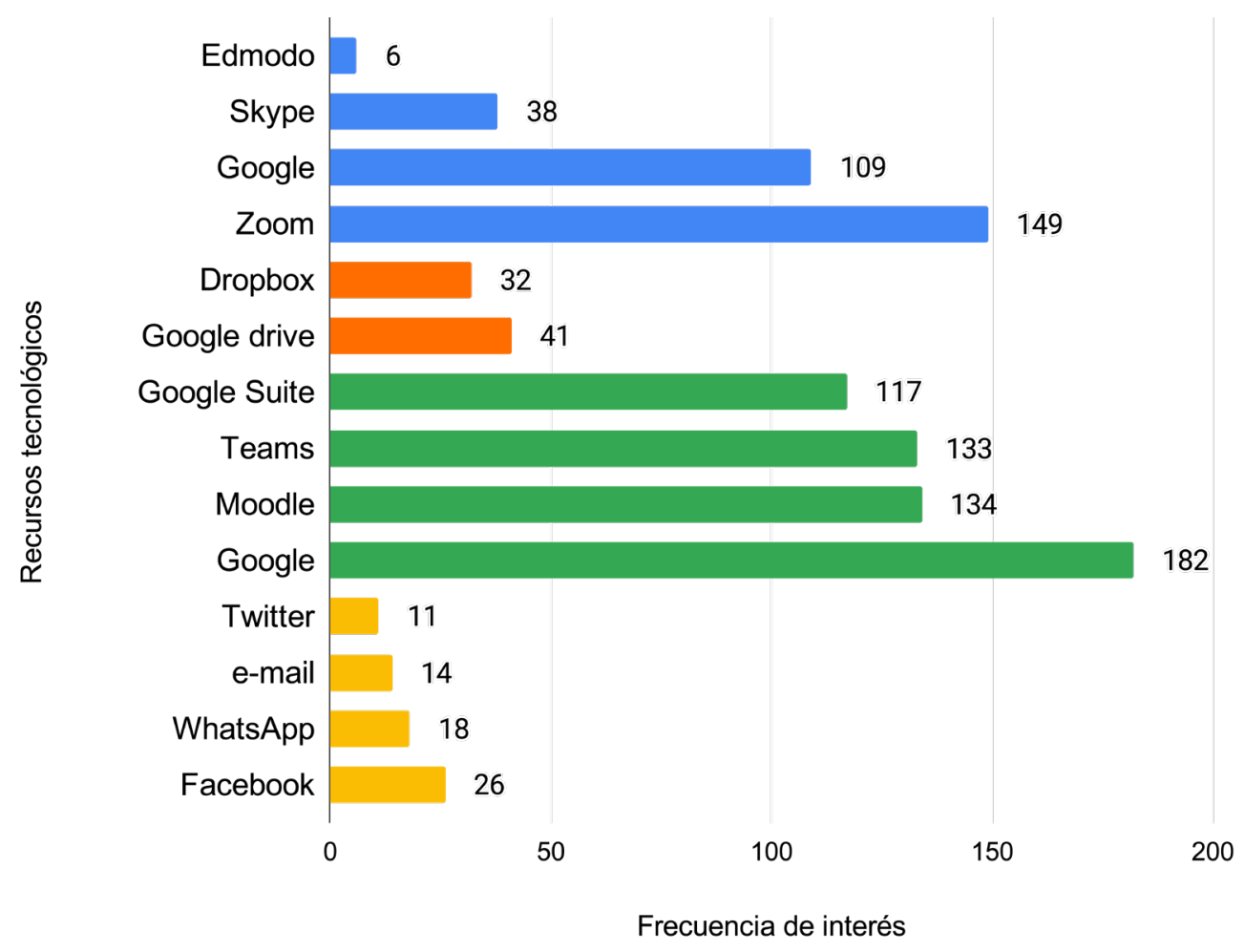

A la pregunta acerca del tipo de apoyo institucional que requieren los docentes para llevar a cabo sus cursos a distancia, respondieron: apoyo técnico para el uso de las herramientas tecnológicas (59.3\%) y asesoría didáctica (40.7\%). Con respecto a los medios por los que preferirían recibir comunicaciones de la institución, $80.7 \%$ dijo que por correo electrónico, 44.9\% por las páginas de internet institucionales, 33.4\% por redes sociales (Facebook, Twitter, WhatsApp) y $25.1 \%$ por el canal de YouTube.

\section{Resultados cualitativos}

En la opción "Otros" de la pregunta 8 ("¿Con qué tipos de problemáticas te estás enfrentando para transformar tus actividades docentes?") se obtuvieron 36 respuestas abiertas que se agruparon en cuatro categorías:

1.La dinámica y carga de trabajo que implica ejercer la docencia de manera no presencial.

2. Las dificultades que los docentes perciben que tienen sus estudiantes, las cuales van desde problemas de actitud y disposición, hasta dificultades en la disponibilidad y uso de las tecnologías.

3. Las situaciones personales de los docentes que dificultan trabajar bajo esta modalidad.

4.Las situaciones institucionales de las dependencias. 
"Retos educativos durante la pandemia de CoviD-19: una encuesta a profesores de la UNAM" Melchor S. Mendiola, María del Pilar M. Hernández, Ruth T. Carrasco, Mercedes de A. Servín, Alan K. Hernández Romo, Mario A. Benavides Lara, Víctor J. Rendón Cazales y Carlos A. Jaimes Vergara

Vol. 21, Núm. 3, mayo-junio 2020 Revista Digital Universitaria

Estas categorías se entienden como problemáticas adicionales a las que contenían las opciones de respuestas y a las que los docentes se están enfrentando.

En la categoría 1, se identifican situaciones relacionadas con la transición que los docentes deben de hacer hacia una modalidad no presencial y ante la cual dicen carecer de condiciones materiales y habilidades, como se ilustra en la siguiente cita:

"En mi caso las actividades están pensadas en curso presencial el uso de la plataforma requiere un diseño instruccional que no tengo diseñado (por razones lógicas) y gasto mucho tiempo en ver dudas, revisar, retroalimentar, además de que muchos alumnos no se han conectado".

En la categoría 2, se encuentran aquellas respuestas que ubican la problemática en los estudiantes y que en la pregunta 9 se trata de explorar con mayor amplitud; sin embargo, destaca la transferencia de la responsabilidad que los docentes hacen hacia los estudiantes y que sitúa la problemática como un tema de actitud.

"Que, en los estudiantes, no veo su interés y espero que los resultados sean favorables".

Sobre las categorías 3 y 4, aunque obedecen a dos situaciones que en apariencia pueden no tener relación, lo personal y lo institucional, es importante replantear ambas problemáticas en tanto el docente no puede concebirse como un sujeto unidimensional, sino como sujeto que posee una historia personal (Tardfiff, 2014), que a veces ve dificultado su desempeño en tanto tiene que cumplir con responsabilidades familiares o laborales, que se hacen patentes en una situación de contingencia como la que se vive. Esto queda de manifiesto en el siguiente testimonio, el cual también sugiere una situación de género:

"Es complicado trabajar en casa y lidiar con las tareas del hogar todo al mismo tiempo".

En ese sentido, lo institucional más que una problemática debería de concebirse como un sistema de apoyo que el docente conoce para llevar a cabo su tarea de la mejor manera posible.

"Prácticamente nos faltaban 2 semanas para concluir el ciclo escolar y sólo solicitamos algunas tareas para su entrega vía correo electrónico, sin embargo, considero muy importante conocer el Campus virtual de la CUAED".

En el caso de la opción "Otros" de la pregunta 9 ("Desde tu perspectiva ¿con qué tipos de problemáticas se están enfrentando tus estudiantes para continuar con tus cursos a distancia?"), ésta también presentó una proporción baja de respuestas abiertas. Dado que es una pregunta sobre las problemáticas que los docentes perciben que tienen sus estudiantes, la información que pueden proveer puede presentar sesgos. A pesar de ello, se destaca que la problemática percibida se puede resumir en las dificultades pedagógicas de transitar de una modalidad presencial y tradicional a una modalidad no presencial, lo cual es consistente con los resultados de la pregunta 8. Las respuestas abiertas para esta pregunta se agruparon en las siguientes categorías: 
"Retos educativos durante la pandemia de CoviD-19: una encuesta a profesores de la UNAM"

1. Baja disposición y actitud que los docentes perciben en sus estudiantes.

2. Falta de habilidades digitales y de estudio que los docentes perciben en sus estudiantes para poder trabajar bajo una modalidad no presencial.

3. Limitado o nulo acceso a la tecnología que los docentes identifican que sus estudiantes tienen debido a carencias económicas.

4. Problemas de comunicación entre docentes y estudiantes.

Más allá de la identificación de las problemáticas a las que se enfrentan los estudiantes, lo que importa de esta pregunta es la idea que los docentes tienen sobre su estudiantado. Las dos primeras categorías se construyen bajo la idea de que, como en el caso de la categoría 2 de la pregunta anterior, se transfiere en alguna medida la responsabilidad de la eficacia de la práctica escolar a una situación de actitudes y disposición que se concentra en el estudiante. Sin restar peso al tema actitudinal del estudiantado, queda el punto de las dificultades que los docentes están teniendo para adaptar su práctica y a partir de ella detonar el interés y participación de sus estudiantes. Y también queda la duda acerca de los procesos de autorregulación y autobservación del profesor sobre sus propias competencias pedagógicas para la enseñanza a distancia y del conocimiento del contenido, además del conocimiento tecnológico; lo que se conoce como el conocimiento tecnológico, pedagógico y del contenido (TPACK, por sus siglas en inglés, Bahcivan y Cobern, 2016; Glowats y O’Brien, 2017; Rienties, et al., 2013).

Respecto de la pregunta 17, la cual pide a los docentes realizar propuestas concretas para que la Universidad los apoye ante la contingencia, se pudieron identificar siete categorías o temáticas que agrupan 407 respuestas. En la figura 13, se observa la distribución de categorías.

Figura 13. Categorías de propuestas de los docentes a la institución (407 respuestas).

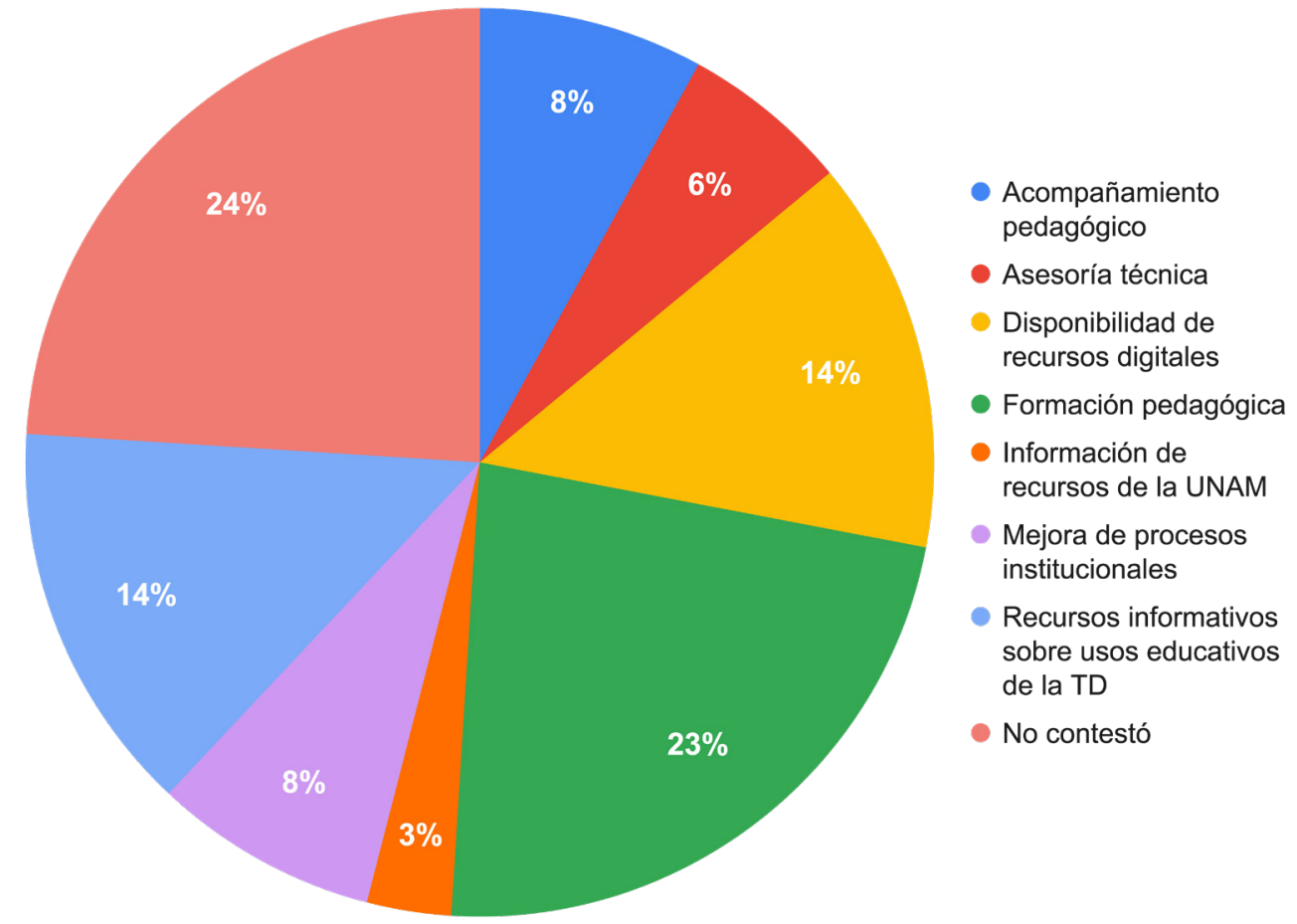


"Retos educativos durante la pandemia de CoviD-19: una encuesta a profesores de la UNAM" Melchor S. Mendiola, María del Pilar M. Hernández, Ruth T. Carrasco, Mercedes de A. Servín, Alan K. Hernández Romo, Mario A. Benavides Lara, Víctor J. Rendón Cazales y Carlos A. Jaimes Vergara

Vol. 21, Núm. 3, mayo-junio 2020 Revista Digital Universitaria

Si bien hubo muchos docentes que no contestaron esta pregunta (24\%), se pueden apreciar dos temáticas importantes: la formación pedagógica (23\%) y la disponibilidad de recursos digitales (14\%).

La categoría en que más docentes coincidieron fue la de formación pedagógica, con 23\% de las respuestas. En ésta se agruparon propuestas que resaltan la necesidad de procesos formativos de actualización docente para apropiarse de recursos digitales útiles para llevar a cabo sus clases a distancia.

De esta manera, se hizo referencia a la necesidad de formarse alrededor de aspectos como la manera de redistribuir el tiempo, el conocimiento de herramientas digitales, el diseño instruccional en una plataforma en línea, las formas de evaluación y la creación de contenidos, entre otras cosas. Algunos ejemplos de estas respuestas son las siguientes:

"En general, a través de mi dependencia estoy siendo apoyada. Pero me gustaría recibir cursos de capacitación tecnológica para aprender a manejar más y mejor las tics".

"Otorgar clases sobre didáctica, manejo de grupo y control emocional de grupos online".

"Tal vez el mayor reto es la evaluación a distancia. Propuesta de estrategias de evaluación a distancia".

Estos ejemplos resaltan la necesidad de formación profesional relacionada con aspectos sobre el uso y manejo de las tecnologías, pero no de forma instrumental, sino de un uso contextualizado relacionado con la didáctica, las dinámicas grupales, las interacciones y las formas de evaluación, entre otras cosas, que son aspectos educativos que se presentan en el trabajo mediado por algún entorno virtual.

Este aspecto también refleja el desconocimiento de muchos de los docentes sobre cómo incorporar las tecnologías digitales para fines académicos; es decir, si bien algunos pueden emplear diversas tecnologías en su vida cotidiana, muchos no han incorporado estos recursos en sus asignaturas y las actividades que ocurren en el aula. Existen dudas sobre cómo continuar la planeación que tenían en las clases presenciales y cómo, bajo las actuales circunstancias, las actividades planeadas podrían adaptarse o continuar usándose. Así, esta categoría está alineada con las problemáticas expresadas por los propios docentes en la pregunta 8.

La disponibilidad de recursos digitales fue la segunda categoría en la que más se agruparon las propuestas hechas por los docentes, ésta hace referencia a las condiciones materiales que son necesarias para el desarrollo óptimo de las clases a distancia a través de medios digitales. Las propuestas de los docentes se dirigieron al aspecto de la infraestructura digital necesaria, lo cual implica la disponibilidad de dispositivos y 28 herramientas digitales como equipos de cómputo, plataformas adecuadas, cuentas de correo institucionales, conectividad a internet con un ancho de banda adecuado, entre otros. De esta manera, algunos docentes afirmaron la necesidad de: 
"Retos educativos durante la pandemia de Covid-19: una encuesta a profesores de la UNAM" Melchor S. Mendiola, María del Pilar M. Hernández, Ruth T. Carrasco, Mercedes de A. Servín, Alan K. Hernández Romo, Mario A. Benavides Lara, Víctor J. Rendón Cazales y Carlos A. Jaimes Vergara

Vol. 21, Núm. 3, mayo-junio 2020

Revista Digital Universitaria

"Apoyos para los estudiantes que no tienen acceso a recursos tecnológicos para que puedan incorporarse a esta forma de trabajo".

"Recursos de ancho de banda para agilizar la comunicación y transferencia de datos".

"La impartición de clases se está llevando desde casa, pero con celular propio. Para impartir clases que impacten en el aprendizaje del alumno, es necesario contar con herramientas para uso a distancia, laptop o PC, pizarrón blanco o pizarrón electrónico, al menos Tablet de 10".

"Sólo la tecnología que una computadora de hace 6 años pueda manejar. Windows 7".

Como se puede apreciar en el primer comentario, los docentes no sólo se preocupan por sus propias condiciones, sino que también tienen en cuenta las condiciones de sus estudiantes; esto a su vez es consistente con lo reportado en la pregunta 9. Los otros ejemplos de respuestas hacen referencia a dispositivos y conectividad, aunque el último comentario resalta las condiciones de acceso que incluyen equipos desactualizados, equipos viejos y posiblemente dañados, motivo por el cual puede haber dificultades para emplear los recursos que se están ofreciendo a los docentes. En estos casos, es necesario contar con alternativas para quienes tienen ese tipo de dificultades, ya que la necesidad expresada por los docentes se incrementó conforme pasaban los días, quizá tras haber evaluado el funcionamiento de los dispositivos y recursos digitales, y después de sus experiencias concretas en los primeros días de la contingencia sanitaria.

Para los lectores interesados, el reporte completo del cuestionario se encuentra disponible como anexo 2.

\section{Discusión y conclusiones}

La contingencia derivada de la pandemia covid-19 ha puesto contra la pared a gobiernos, sistemas de salud, a la economía global y a las instituciones educativas (Sanz, 2020). En el caso de la educación superior uno de los efectos inmediatos más importantes es el súbito golpe de timón para migrar totalmente a la modalidad de educación a distancia, a través de educación mediada por tecnología (The Chronicle of Higher Education, 2020). Esta repentina nueva realidad ha puesto en una situación inesperada a los docentes de educación superior que, además de atender su situación personal, familiar y profesional (en el caso de actividades esenciales), tienen la responsabilidad de dar continuidad a las actividades de enseñanza con sus estudiantes, lo que está generando una gran cantidad de situaciones complejas que deben enfrentarse a corto, mediano y largo plazo, para disminuir, en lo posible, el impacto en el aprendizaje y la formación profesional de los estudiantes universitarios (Sanz, 2020).

En esta situación es fundamental aprender las lecciones de otros países en cuanto a las decisiones de los gobiernos y sistemas de salud para prevenir y atender a la población acerca de la pandemia por covid-19, y al manejo de estrategias y políticas de salud pública, como son el uso de pruebas diagnósticas para el virus y la pronta adopción de medidas de distanciamiento social. 
"Retos educativos durante la pandemia de Covid-19: una encuesta a profesores de la UNAM" Melchor S. Mendiola, María del Pilar M. Hernández, Ruth T. Carrasco, Mercedes de A. Servín, Alan K. Hernández Romo, Mario A. Benavides Lara, Víctor J. Rendón Cazales y Carlos A. Jaimes Vergara

Vol. 21, Núm. 3, mayo-junio 2020

Revista Digital Universitaria

Aunque en lo que respecta a los aspectos sociales de la educación, es crucial tomar en cuenta el contexto local. Por ello, es indispensable identificar las problemáticas que viven los docentes y estudiantes de nuestro medio, para estar en condiciones de tomar decisiones razonadas, razonables e informadas por nuestra realidad. Por lo anterior, la unam realizó el presente estudio, en una muestra de profesores de los diferentes niveles educativos que se imparten, para obtener con rapidez un diagnóstico sobre algunos elementos de información necesarios, que permitieran retroalimentar a las autoridades universitarias en general, a los directores de facultades y escuelas en particular, así como a los docentes mismos, con el fin de continuar enfrentando, de la forma más focalizada posible, el problema educativo que está afectando gravemente al sistema educativo nacional.

Comienzan a surgir reportes formales de los problemas a los que se están enfrentando los docentes de educación superior en nuestro medio, pero hasta donde pudimos investigar, el presente reporte es el primero de nuestra institución. La tasa de respuesta que se obtuvo fue elevada para una encuesta en línea, de casi 50\%, cuando generalmente la respuesta a esta modalidad de cuestionarios es baja - aproximadamente 33\%—, comparada con las encuestas cara a cara, que es de 56\%, aunque se realicen con buenas prácticas (Duncan, 2008). En la actualidad, como nos consta a los académicos que realizamos investigación en educación, la tasa de respuesta a cuestionarios en línea ha disminuido dramáticamente, en algunos casos es menor a 10\%, porcentaje con el que es difícil establecer inferencias apropiadas. En nuestro estudio, la sencillez del instrumento y el corto tiempo requerido para su respuesta probablemente contribuyeron a la elevada tasa de respuesta, pero, sobre todo, creemos que jugó a nuestro favor la intensa motivación de los docentes en el contexto actual de incertidumbre y necesidad de ayuda.

En el estudio obtuvimos respuestas predominantemente de mujeres docentes (56.1\%), lo cual contrasta con la composición de la población académica de la UNAm, en la que las mujeres son aproximadamente 45\% del profesorado (Sánchez Mendiola, 2019). Debe recordarse que la población que respondió el cuestionario provenía del registro de docentes que han participado en actividades de educación continua de la codeIc, la cual reúne una mayor cantidad de docentes mujeres (64\%); esta diferencia de género podría deberse a que las profesoras, por diversas razones, tienden a asistir con mayor frecuencia a actividades de educación continua que los profesores (Toutkoushian, 1999).

Por otra parte, de los docentes que respondieron la encuesta 70\% corresponde a profesores de asignatura, cifra que concuerda con el porcentaje global de académicos de la unAm con este nombramiento, que es de aproximadamente $67.1 \%$. La mayoría de los profesores en nuestra institución son de asignatura, y pudiera ser que son los que más buscan actividades de formación docente (Sánchez Mendiola, 2019). 
"Retos educativos durante la pandemia de CoviD-19: una encuesta a profesores de la UNAM" Melchor S. Mendiola, María del Pilar M. Hernández, Ruth T. Carrasco, Mercedes de A. Servín, Alan K. Hernández Romo, Mario A. Benavides Lara, Víctor J. Rendón Cazales y Carlos A. Jaimes Vergara

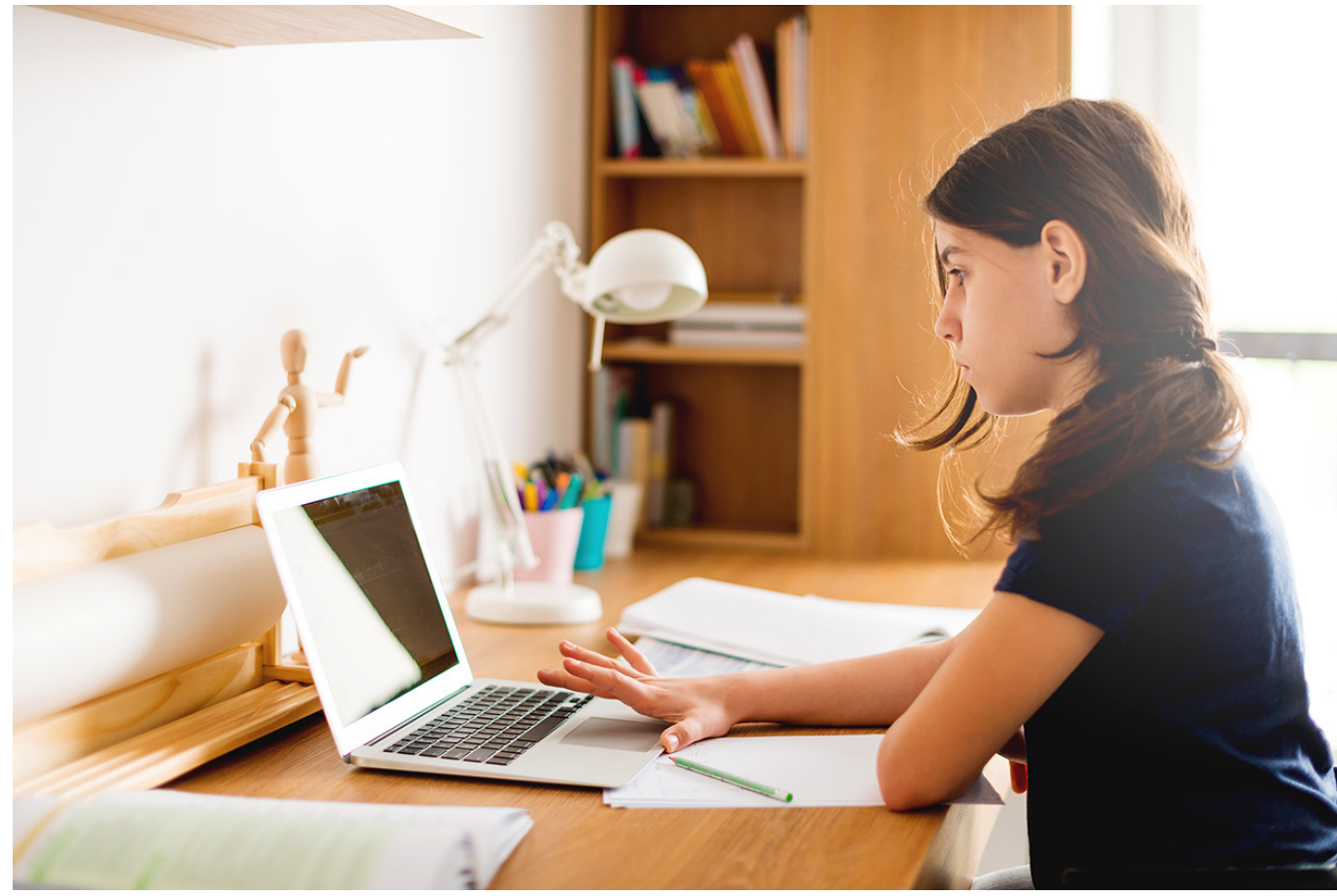

El reto de la educación a distancia varía sustancialmente por nivel educativo. No es lo mismo enseñar a estudiantes de bachillerato, que de licenciatura o de posgrado, ya que la autonomía para el aprendizaje de las experiencias en la escolaridad previa de educación superior, el nivel de conocimientos y el dominio de habilidades es diferente, así como la estructura y el nivel de profundidad de los planes y programas de estudio, los métodos de enseñanza y el número de estudiantes por grupo. La mayoría de los docentes que respondieron el cuestionario son profesores de licenciatura, aunque están representados también profesores de bachillerato y posgrado. Llama la atención que hay un número sustancial de profesores que tienen más de dos grupos, principalmente en bachillerato y licenciatura, la mayor parte de los cuales está compuesto por 40 estudiantes o más. Algunos docentes tienen simultáneamente más de cuatro grupos y, por consiguiente, atienden a más de 80 estudiantes, lo que los coloca en situación particularmente difícil para desarrollar actividades educativas no presenciales satisfactorias.

En educación en línea, el número óptimo de estudiantes por grupo es variable, dependiendo del nivel educativo, los objetivos del currículo, las habilidades y experiencia en el uso de tıc de docentes y estudiantes. La literatura sugiere que, para docentes noveles en educación a distancia, un tamaño de clase de 12 estudiantes por instructor es apropiado (Sieber, 2005). Algunos autores sugieren que el límite superior para atender adecuadamente a estudiantes de pregrado es de 20 por clase, y para el posgrado de 8 a 15 estudiantes por instructor (Taft, 2011), lo cual es muy difícil de lograr en universidades públicas de países como el nuestro. Es importante tratar de lograr un tamaño de clase 
"Retos educativos durante la pandemia de Covid-19: una encuesta a profesores de la UNAM" Melchor S. Mendiola, María del Pilar M. Hernández, Ruth T. Carrasco, Mercedes de A. Servín, Alan K. Hernández Romo, Mario A. Benavides Lara, Víctor J. Rendón Cazales y Carlos A. Jaimes Vergara

Vol. 21, Núm. 3, mayo-junio 2020

Revista Digital Universitaria

que logre un balance adecuado de interacción en el curso, "ni tan grande que los estudiantes se sientan perdidos y desconectados, ni tan pequeño que haya muy pocas oportunidades de interacción" (Burruss et al., 2009).

En México existe una importante presión para que las universidades públicas incrementen su matrícula, por lo que nuestras instituciones tienden a hacerlo en la modalidad a distancia, ya que existe la falsa creencia de que este tipo de enseñanza es menos exigente, con aprendizajes de menor calidad, que se requieren menos aulas y profesores, $y$, en general, que es menos efectiva y deseable por los estudiantes que la educación presencial. Pero es un hecho que la educación en línea requiere más carga de trabajo por parte del docente, comparada con la educación tradicional y, por lo menos, 14\% más de inversión de tiempo (Tomei, 2006). La emergencia actual nos está demostrando la importancia de la incorporación del trabajo en línea en combinación con el trabajo presencial, que es fundamental que las universidades utilicemos la evidencia publicada sobre la educación a distancia para la toma de decisiones institucionales, y que hagamos un gran esfuerzo para adaptar nuestras necesidades a la realidad local (Samperio-Pacheco y Barragán-López, 2018).

En las respuestas de la encuesta, 60.5\% de los docentes está de acuerdo con el apoyo institucional que ha recibido para realizar sus tareas educativas en el momento inicial de la contingencia. Sin embargo, conforme transcurra el tiempo y se prolongue la suspensión de actividades presenciales en las universidades, este porcentaje puede cambiar al adquirir conciencia de que ya no se trata solamente de una respuesta urgente a una situación aguda, sino de una necesidad cuasi permanente de utilizar la educación a distancia como una modalidad educativa prácticamente obligatoria. No es lo mismo responder a una catástrofe masiva mostrando solidaridad y entusiasmo, que incorporar las actividades que no se estaba acostumbrado a realizar en la cotidianeidad (Hodges, 2020).

Por otra parte, cerca de la mitad de los docentes de esta muestra desconocían la existencia del Campus Virtual de la unam (https://distancia.cuaed. unam.mx/campusvirtual.html), la respuesta institucional más importante para enfrentar la transición de la modalidad presencial a la educación a distancia. Esto sugiere que lo abrupto del cambio rebasó, en cierta manera, la capacidad de comunicación institucional en una organización tan heterogénea y compleja como la nuestra. Seguramente esta cifra ha disminuido notoriamente en los últimos días, al realizarse una intensa campaña de difusión para el uso de este recurso. Incluso la misma encuesta sirvió de vehículo de información al hacer la pregunta, ya que se acompañaba de la liga del sitio del Campus Virtual.

Los retos que enfrentamos los docentes para usar las tecnologías de información y comunicación (TIC) y transformar su uso meramente técnico al manejo de herramientas pedagógicamente útiles (TAC, tecnologías para el aprendizaje y el conocimiento) han sido ampliamente estudiados a nivel global y en nuestra institución (Zubieta, Bautista y Quijano, 2012). En nuestro estudio encontramos que los docentes afirman que las problemáticas logísticas y 
"Retos educativos durante la pandemia de Covid-19: una encuesta a profesores de la UNAM" Melchor S. Mendiola, María del Pilar M. Hernández, Ruth T. Carrasco, Mercedes de A. Servín, Alan K. Hernández Romo, Mario A. Benavides Lara, Víctor J. Rendón Cazales y Carlos A. Jaimes Vergara

Vol. 21, Núm. 3, mayo-junio 2020

Revista Digital Universitaria

tecnológicas son las más importantes, seguidas por las pedagógicas y en último lugar las socioafectivas. Estos datos sugieren que la inmediatez del reto y la muralla virtual de la pobre infraestructura de comunicaciones de nuestro país, así como la brecha digital existente entre diversos sectores de la sociedad (tanto en docentes como en estudiantes), hacen que estas problemáticas estén en la mira inmediata del profesorado. Por supuesto que es prácticamente imposible realizar educación mediada por tecnología si se carece de la misma, o ésta es de calidad subóptima, por lo que dicha percepción es entendible. A corto, mediano y largo plazo, las universidades y las autoridades de cada país necesitan realizar acciones efectivas y hacia la democratización de las TAc para que esta brecha tecnológica disminuya, y que los estudiantes y profesores que no tienen acceso a la red, o que no tienen dispositivos digitales en casa, reciban de alguna manera apoyo institucional para cubrir estas carencias, además de que tanto ellos como quienes sí los tienen accedan a la educación con las condiciones adecuadas. Llama la atención que las problemáticas pedagógicas y socioafectivas se consideran menos importantes, lo que seguramente cambiará conforme progrese y se mantenga el cierre de las actividades presenciales. Estas problemáticas, no por ser mencionadas como menos importantes no deben tomarse en cuenta, ya que la efectividad de la enseñanza y el aprendizaje dependen de que las actividades educativas tengan fundamentos pedagógicos, y que los profesores y alumnos tengan un mínimo de estabilidad socioemocional (Tyng Cha, 2017).

Las herramientas utilizadas por los docentes para comunicación, trabajo académico, trabajo sincrónico y almacenamiento son similares a las publicadas en la literatura internacional y nacional (Zubieta, Bautista y Quijano, 2012). Estas herramientas han ido evolucionando en las últimas décadas, pero su intencionalidad se ha mantenido más o menos estable, es decir, necesitamos tecnologías para buscar y compartir información, para interactuar con colegas y estudiantes, y para almacenar y distribuir lecturas, videos o tareas. Tal vez una de las lecciones más importantes del momento actual es que la diseminación del uso de estas herramientas en la comunidad de profesores y en las entidades en que se desempeñan ha sido demasiado lenta, y hasta que nos vimos inmersos en una contingencia como la presente las estamos incorporando, sencillamente porque no hay alternativa. A partir de ahora no tenemos pretexto para no participar en actividades de formación docente que nos hagan más diestros en el uso de la tecnología, para nuestro desarrollo profesional continuo en lo personal, y para beneficio de los estudiantes a los que nos debemos. Las instituciones educativas y el gobierno también deben tomar nota de que el uso de las tecnologías no debe ser una opción o un "adorno", sino que necesitan convertirse en componente fundamental de los programas de formación y profesionalización en educación para los docentes y de los recursos dispuestos para los estudiantes. Pedimos a los lectores que tienen acceso a internet de banda ancha, con dispositivos digitales modernos en su casa, que se imaginen el confinamiento prolongado sin estos recursos. El acceso a internet y al conocimiento universal debe convertirse en un derecho humano no sólo en la retórica, sino en la realidad. 
"Retos educativos durante la pandemia de Covid-19: una encuesta a profesores de la UNAM" Melchor S. Mendiola, María del Pilar M. Hernández, Ruth T. Carrasco, Mercedes de A. Servín, Alan K. Hernández Romo, Mario A. Benavides Lara, Víctor J. Rendón Cazales y Carlos A. Jaimes Vergara

Vol. 21, Núm. 3, mayo-junio 2020 Revista Digital Universitaria

Un componente interesante de nuestro estudio es su parte cualitativa. La mayoría de los cuestionarios se limitan a preguntas cerradas que arrojan información cuantitativa, pero cuando se incluyen preguntas abiertas, éstas generalmente se dejan de lado como meras anécdotas. Estamos convencidos de que la interpretación de los testimonios y narrativas de los docentes son un elemento indispensable para desentrañar lo que ocurre en la realidad, que nos ayuda a comprender lo que viven los docentes y cómo podemos interpretarlo. En este sentido, el análisis e identificación de temas en las respuestas abiertas proporcionó información de gran utilidad para entender el reto al que se enfrentan y cómo puede la institución ayudarlos a solventarlos. La propuesta más importante de los docentes es la formación pedagógica, con todo lo que implica. Esto es fundamental ya que, como hemos comentado anteriormente, el proceso de desarrollo de los docentes es una de las tareas más importantes que debe promover la Universidad (Sánchez Mendiola, 2019). Ante el reto que representa la pandemia y sus consecuencias económicas, psicológicas y sociales, una de las principales estrategias que debemos adoptar en las instituciones educativas es la formación y profesionalización en pedagogía y didáctica para la enseñanza y el aprendizaje universitarios, tomando en cuenta la infraestructura, las competencias y habilidades en tecnologías para el aprendizaje y el conocimiento. Los testimonios de los docentes en cuanto a recursos tecnológicos, procesos institucionales, acompañamiento pedagógico y tecnológico, entre muchos otros, deben convertirse en fuertes llamadas de atención para las autoridades de las múltiples dependencias y entidades académicas que laboramos en la Universidad. Debemos inspirarnos en estas perlas de expresión de nuestros docentes, para adoptar actitudes positivas y desarrollar estrategias educativas creativas e innovadoras para enfrentar la situación ahora y en el futuro mediato.

\section{Referencias}

* Bahcivan, E. and Cobern, W. W. (2016). Investigating Coherence among Turkish Elementary Science Teachers' Teaching Belief Systems, Pedagogical Content Knowledge and Practice [Investigando la coherencia entre los sistemas de creencias, el conocimiento del contenido pedagógicoyla práctica]. Australianjournal of Teacher Education, 41(10): 63-86. https://doi.org/10.14221/ajte.2016v41n10.5.

- Glowatz M. and O’Brien O. (2017). Academic Engagement and Technology: Revisiting the Technological, Pedagogical and Content Knowledge Framework (TPACK) in Higher Education (HE): The Academics' Perspective [Compromiso académico y tecnología: Revisión del Marco de Conocimiento Tecnológico, Pedagógico y de Contenidos (TPACK) en la Educación Superior (ES): La perspectiva de los académicos]. IAFor Journal of Education, 5 [special issue],133-159. https://doi. org/10.22492/ije.5.si.06. 
"Retos educativos durante la pandemia de CoviD-19: una encuesta a profesores de la UNAM" Melchor S. Mendiola, María del Pilar M. Hernández, Ruth T. Carrasco, Mercedes de A. Servín, Alan K. Hernández Romo, Mario A. Benavides Lara, Víctor J. Rendón Cazales y Carlos A. Jaimes Vergara

Vol. 21, Núm. 3, mayo-junio 2020 Revista Digital Universitaria

* Han, C. (2008) Doing Qualitative Research Using Your Computer [Hacer investigación cualitativa usando su computadora]. Sage Publications. https://doi. org/10.4135/9780857024411.

Hodges, C., Moore, S., Lockee, B., Trust, T., y Bond, A. (2020). The Difference Between Emergency Remote Teaching and Online Learning [La diferencia entre la emergencia de la enseñanza a distancia y el aprendizaje en línea]. EDUCAUSE Review. https://er.educause.edu/articles/2020/3/the-difference-between-emergencyremote-teaching-and-online-learning.

* Rienties, B.; Brouwer, N. y Lygo-Baker, S. (2013). The effects of online professional development on higher education teachers' beliefs and intentions towards learning facilitation and technology [Los efectos del desarrollo profesional en línea en las creencias e intenciones de los profesores de enseñanza superior en cuanto a la facilitación del aprendizaje y la tecnología]. Teaching and Teacher Education, 29,122-131. http://dx.doi.org/10.1016/j.tate.2012.09.002.

* Samperio-Pacheco, V. M. y Barragán-López, J. F. (2018). Análisis de la percepción de docentes, usuarios de una plataforma educativa a través de los modelos TPACK, SAMR Y TAM3 en una institución de educación superior. Revista de innovación educativa, 10(1): 116-131. http://www.udgvirtual.udg.mx/apertura/index.php/ apertura/article/view/1162/859.

* Sánchez Mendiola, M. y Martínez Hernández, A. (Eds.). (2019). Formación Docente en la UNAM: Antecedentes y la Voz de su Profesorado. Coordinación de Desarrollo Educativo e Innovación Curricular, unAM.

* Sanz, I., Sáinz González, J., Capilla, A. (2020). Efectos de la Crisis del Coronavirus en la Educación Superior. Organización de Estados Iberoamericanos para la Educación, la Ciencia y la Cultura (oEI). https://oei.org.br/arquivos/informe-covid-19d.pdf.

* Sieber, J. (2005). Misconceptions and realities about teaching online [Conceptos erróneos y realidades sobre la enseñanza en línea]. Science and Ethics, 11, 329340. https://doi.org/10.1007/s11948-005-0002-7.

* Tardiff, M. (2014). Los saberes del docente y su desarrollo profesional. nARCEA.

* Taft, S.H., Perkowski, T. y Martin, L.S. (2011). A Framework for Evaluating Class Size in Online Education [Un marco para evaluar el tamaño de las clases en la educación en línea]. The Quarterly Review of Distance Education, 12, 3, 181-197. https://oaks.kent.edu/nurspubs/1.

Toutkoushian, R. K. y Bellas, M. L. (1999). Faculty Time Allocations and Research Productivity: Gender, Race and Family Effects [Asignación de tiempo del profesorado y productividad de la investigación: Efectos sobre el género, la raza y la familia]. The Review of Higher Education, 22(4), 367-390. https://doi.org/10.1353/ rhe.1999.0014.

- The Chronicle of Higher Education. (2020). Moving Online Now. How to Keep Teaching during Coronavirus [Moverse en línea ahora. Cómo seguir enseñando durante el Coronavirus]. https://connect.chronicle.com/CS-WC-2020CoronavirusFreeReport LP-SocialTraffic.html. 
"Retos educativos durante la pandemia de CoviD-19: una encuesta a profesores de la UNAM" Melchor S. Mendiola, María del Pilar M. Hernández, Ruth T. Carrasco, Mercedes de A. Servín, Alan K. Hernández Romo, Mario A. Benavides Lara, Víctor J. Rendón Cazales y Carlos A. Jaimes Vergara

Vol. 21, Núm. 3, mayo-junio 2020 Revista Digital Universitaria

* Tomei, J. (2006). The impact of online learning on faculty load: Computing the ideal class size for online learning [El impacto del aprendizaje en línea en la carga del profesorado: Computar el tamaño ideal de la clase para el aprendizaje en línea]. Journal of Technology and Teacher Education, 14, 531-541. https://eric. ed.gov/?id=EJ729637.

Tyng Chai, M., Amin Hafeez, U., Saad Mohamad, N. M. y Malik Aamir, S. (2017). The Influences of Emotion on Learning and Memory [Las influencias de la emoción en el aprendizaje y la memoria]. Frontiers in Psychology, 8, 1454. https://doi. org/10.3389/fpsyg.2017.01454.

* Universidad Nacional Autónoma de México (UnAm). (2020). La unam en números. Consultado el 7 de abril de 2020. http://www.estadistica.unam.mx/numeralia/.

- Van Dijk, T. (2000). El discurso como estructura y proceso, estudios sobre el discurso [tomo I]. Editorial Gedisa.

* Yi, Y., Lagniton, P., Ye, S., Li, E., y Xu, R. H. (2020). covid-19: what has been learned and to be learned about the novel coronavirus disease [CoviD-19: lo que se ha aprendido y lo que se debe aprender sobre la nueva enfermedad del coronavirus]. International Journal of Biological Sciences, 16, 10, 1753-1766. https:// doi.org/10.7150/ijbs.45134.

- Zubieta García, J., Bautista Godínez, T. y Quijano Solís, Á. (2012). Aceptación de las TIC en la Docencia: Una Tipología de los Académicos de la UNAM. UnAM; Porrúa. https:// maporrua.com.mx/product/aceptacion-de-las-tic-en-la-docencial.

\section{Cómo citar este artículo}

* Sánchez Mendiola, M., Martínez Hernández, A. M., Torres Carrasco, R., de Agüero Servín, M., Hernández Romo, A. K., Benavides Lara, M. A., Rendón Cazales, V. J. y Jaimes Vergara, C. A. (2020). Retos educativos durante la pandemia de coviD-19: una encuesta a profesores de la unAm. Revista Digital Universitaria (RDU) Vol. 21, núm. 3 mayo-junio. Dol: http://doi.org/10.22201/codeic.16076079e.2020.v21n3.a12.

Recepción: 12/04/2020. Aceptación: 05/05/2020. 